\title{
Las niñas y los niños del destierro. Indígenas y afrodescendientes en la ciudad
}

\author{
BOYS AND GIRLS OF EXILE: AFRO-DESCENDANTS AND INDIGENOUS PEOPLE IN THE CITY \\ aS CRIANÇAS DO DESTERRO. INDÍGENAS E AFRODESCENDENTES NA CIDAD
}

\author{
Elizabeth Castillo Guzmán*
}

\section{Resumen}

Según las cifras oficiales de la Organización de las Naciones Unidas (ONU), Colombia es la segunda nación del planeta con población en situación de desplazamiento forzado. Este fenómeno complejo y de larga data tiene una expresión muy dramática en lo que se refiere a la situación de la niñez indígena y afrodescendiente en los entornos urbanos contemporáneos a los cuales han sido desterradas familias y comunidades de diferentes regiones del país. Este artículo pretende sensibilizar a la comunidad de pedagogos, formadores de docentes e investigadores educativos respecto de los derechos de esta niñez en los sistemas escolares de ciudades como Bogotá. Nos valemos de algunos testimonios que reflejan las difíciles y desiguales circunstancias que enfrentan muchos de ellos y muchas de ellas al interior de la escuela urbana y sus culturas pedagógicas, para resaltar el papel que cumple la escuela en el tratamiento digno de su diferencialidad cultural, lingüística y étnica. Se trata de una reflexión en torno al racismo y a la discriminación que subyacen en un sistema escolar colombiano y sus efectos en la vida niñas y niños.

\section{Abstract}

According to an official report by the United Nations (UN), Colombia is the country with the secondbiggest forced displacement situation in the world. This is an old, complex phenomenon that reflects dramatically on the situation of indigenous and afro-descendant children in the contemporary urban environments to which families and communities from different regions of the country have been banished. This paper aims to raise awareness among the community of teachers, teacher educators and researchers in education about the rights of these children in the school system of cities like Bogotá. We use some testimonies that reflect the difficult and unequal circumstances that many of these boys and girls face in urban schools and their pedagogical cultures in order to highlight the school's role in the rightful treatment of their cultural, linguistic and ethnic differences. It is a reflection on the underlying racism and discrimination in a Colombian school system and how it affects the lives of boys and girls.

\section{Resumo}

Segundo as cifras oficiais da Organização das Nações Unidas (ONU), Colômbia é a segunda nação do planeta com população em situação de deslocação forçada. Este fenômeno complexo e de longa data tem uma expressão muito dramática em relação à situação da infância indígena e afrodescendente nos entornos urbanos contemporâneos, aos quais famílias e comunidades de diversas regiões do país foram desterradas. Este artigo visa sensibilizar a comunidade de pedagogos, formadores de docentes e pesquisadores educativos com respeito aos direitos das crianças nos sistemas escolares de cidades como Bogotá. Utilizam-se alguns testemunhos que refletem as difíceis e desiguais circunstâncias que muitos deles confrontam no interior da escola urbana e suas culturas pedagógicas, ressaltando o papel da escola quanto ao tratamento digno de sua diferença cultural, linguística e étnica. Esta é uma reflexão sobre o racismo e a discriminação subjacentes em um sistema escolar colombiano e seus efeitos na vida das crianças.
Palabras clave

infancia; niñez en situación de desplazamiento; conflicto armado; derechos; grupos étnicos; derechos humanos

\section{Keywords}

infancy; displaced children; armed conflict; rights, ethnic groups; human rights

\section{Palavras chave}

infância; Infância em situação de deslocamento; conflito armado; direitos; grupos étnicos; direitos humanos

Fecha de recepción: 23 de junio de 2016 / Fecha de aprobación: 15 de agosto de 2016

* Universidad del Cauca Popayán, Cauca. Correo electrónico: Icastil@unicauca.edu.co 


\section{Aclaraciones iniciales}

En 2009 realizamos en la ciudad de Bogotá el primer estudio sobre racismo y educación inicial1. Este abrió un ámbito de problemas que no habían sido visibles en los debates académicos sobre la educación colombiana, el conflicto armado y las relaciones de reconocimiento de poblaciones racializadas por cuenta del fenómeno colonial. Los planteamientos de este artículo retoman los resultados que arrojó el estudio referido, y ponen en diálogo las voces de los niños, que hemos recogido en un proceso etnográfico que adelantamos desde 2015 en Bogotá, bajo el proyecto de diálogo de saberes "Niñez, etnicidad y nuevas conflictividades educativas" y que nos ha permitido comenzar a explorar los elementos comprometidos en este nueva etapa de la etnicidad colombiana, y es aquella que corre en escenarios distintos a los de sus contextos originarios y producen fenómenos complejos de hetero y autorreconocimiento de las personas y los colectivos. El punto central sobre el cual queremos insistir es el de la vulnerabilidad que los niños pertenecientes a las comunidades étnicas en situación de desplazamiento en la ciudad, enfrentan diariamente en su paso por centros de atención infantil, escuelas y espacios en los que transcurre su vida cotidiana, debido a que el orden institucional no está preparado para tramitar las demandas educativas y necesidades de bienestar de esta niñez. A este asunto se suman por lo menos dos problemas históricos aún existentes: a) un sistema escolar expandido a lo largo y ancho del país, que no ha logrado pluralizarse a nivel curricular, ni administrativo a pesar de la diversidad cultural y étnica colombiana, y b) como consecuencia de lo primero, el fenómeno estructural de discriminación y racismo que atraviesa nuestra historia social como nación y nuestra convivencia diaria. Esta investigación también nos mostró la importancia de dar voz a los niños para conocer cómo ellos tramitan su propia experiencia en la ciudad y en la escuela. Por esta razón, los aspectos testimoniales que se incluyen en este texto son parte fundamental de nuestra argumentación.

1 Nos referimos al estudio “¿Cómo nos ven, ¿cómo nos representan? Invisibilidad/visibilidad de la afrocolombianidad en los materiales de la educación preescolar en Bogotá", Universidad del Cauca-Unión Americana para la Educación Superior - Secretaría de Educación de Bogotá (2011-2012). El primer estudio sobre racismo escolar lo realizó María Isabel Mena en 2008.
A pesar de que Colombia se ha reconocido en el terreno jurídico como nación multicultural, este rasgo no se ha visto contemplado en las políticas educativas con un esfuerzo decidido en materia de lineamientos curriculares, formación docente, calidad educativa e investigación pedagógica. Amén de esfuerzos de algunos gobiernos de turno en ciudades como Bogotá y Medellín, este asunto sigue estando supeditado a la agenda global que estandariza la educación. En cuanto a la educación inicial, este fenómeno es aún mucho más complejo porque refleja las limitaciones que tenemos para reconocer la existencia de infancias diversas y diferenciadas, cuyas demandas en materia de atención, protección y educación desbordan los parámetros de programas nacionales de primera infancia que tanto auge han cobrado en los últimos años.

\section{El conflicto colombiano y sus impactos en el aula}

La guerra recae especialmente sobre las poblaciones empobrecidas, sobre los pueblos afrocolombianos e indígenas, se ensaña contra los opositores y disidentes, y afecta de manera particular a las mujeres, a los niños y niñas. (Centro Nacional de Memoria Histórica, 2013, p. 25).

El conflicto colombiano del siglo xx se agudizó dramáticamente a partir de los años 1980 y cambió la vida del país, especialmente entre los más empobrecidos y marginalizados. Es el caso de las poblaciones indígenas y afrodescendientes ubicadas en los antiguos territorios nacionales ${ }^{2}$. Según el informe ¡Basta ya! Colombia: memorias de guerra y dignidad, del Centro de Memoria Histórica (2013), las prácticas de violencia ejercidas durante varias décadas produjeron en Colombia cientos de miles de víctimas, personas y familias afectadas en su integridad y su dignidad humana. Al mundo de las escuelas de ciudades y regiones rurales llegaron de diversos modos las resonancias de este drama que nos heredó duelos y olvidos.

2 Desde la Constitución de 1886 quedó establecido la figura de intendencias y comisarías para los denominados territorios nacionales que comprendieron lo que hoy conocemos como departamentos de Arauca, Amazonas, Caquetá, Chocó, Caquetá, La Guajira, Meta, Putumayo, San Andrés y Providencia, Vaupés y Vichada. 
Los impactos psicológicos deterioran las relaciones interpersonales y la salud física; las pérdidas económicas generan inestabilidad emocional; los impactos colectivos y el daño a las redes sociales y comunitarias afectan las capacidades y posibilidades individuales. Así, se configura un entramado de situaciones que se relacionan mutuamente, lo cual hace difícil separar y especificar aquello que es propio de cada tipo de daño. (Centro Nacional de Memoria Histórica, 2013 p. 260).

Poco a poco la escuela se fue convirtiendo en parte de esa cadena de violencias, bien por la incidencia directa de los actores políticos en la administración de los centros educativos, o por el influjo directo de sus actores de carne y hueso, niños, niñas y adolescentes inmersos en la compleja realidad del conflicto armado y sus impactos en la vida cotidiana. La cinta Los colores de la montaña, del director colombiano Carlos Álvarez, es una de las signficativas producciones audiovisuales del finales del siglo xx que da cuenta de lo que significa crecer con miedo a los campos minados, el combate entre grupos enemigos y sin permiso para ser niño o niña. La guerra se tomó los campos colombianos y sus escuelas. Las maestras comenzaron a desplazarse por la inseguridad o por las amenazas contra sus vidas, de igual manera muchos docentes tuvieron que cambiar de sitio de trabajo por la presión de los grupos armados sobre ellos. Muchas escuelas debieron cerrarse por diversas causas derivadas del conflicto armado. Muchos menores cambiaron de lugar de residencia y sus familias se convirtieron en parte de la escandalosa cifra de población desplazada. Las principales ciudades de Colombia se convirtieron, a partir de los años sesenta, en receptoras de gentes provenientes del campo.

\section{Los nuevos habitantes de la educación inicial}

Los lineamientos pedagógicos formulados por el Ministerio de Educación Nacional en materia de educación inicial se caracterizan por la invisibilidad de niños menores de 7 años, pertenecientes a grupos étnicos. Es decir, la política no los nombra, ni les reconoce en la especificidad de sus derechos culturales en tanto y cuanto miembros de comunidades culturalmente diferenciadas (Castillo y Caicedo, 2011). Este aspecto es especialmente relevante si se tiene en cuenta que demográficamente indígenas y afrodescendientes presentan dispersión a lo largo y ancho de la nación, y por tanto es urgente contar con instrumentos de política pública que reconozcan y asuman la existencia de infancias diferenciadas, que demandan en materia pedagógica y de protección consideraciones especiales respecto de sus derechos y necesidades.

Existe una invisibilidad en la política pública que oculta bajo nociones educativas globales, universalismos, orientaciones y estándares de calidad la diferencialidad que portan los niños indígenas y afrocolombianos, como así también su vulnerabilidad en un contexto donde son población minoritaria en términos raciales y culturales.

En el mismo sentido, los lineamientos de entidades distritales oficiales en Bogotá, como las secretarías de Educación y de Integración Social promueven, desde principios del siglo xxı, un enfoque general en relación con el tratamiento de la diversidad. Sin embargo, solo en el caso de la población indígena, la ciudad cuenta recientemente con unos parámetros pedagógicos para la atención de la población infantil cubierta por centros e instituciones de la Secretaría de Integración Social del Distrito (SIDIS) (2011). En otro plano, debe señalarse que el conjunto de la política para la primera infancia no incluye la perspectiva diferencial que implica la pertenencia étnica de los niños, por esta razón se presentan tensiones entre las concepciones promovidas desde las políticas nacionales y las provenientes de los procesos familiares y comunitarios. Aquí queda planteado un debate respecto a los enfoques multiculturales o interculturales que deben prevalecer en el diseño de programas y políticas educativas para contextos multiculturales.

Un rasgo que agudiza esta situación es la falta de preparación de los docentes del sector educativo para tramitar pedagógicamente los asuntos de las diferencias étnicoraciales presentes en la socialización de nuestras nuevas generaciones. Algunos estudios realizados en Bogotá han mostrado que existe un grave problema de racismo entre muchos educadores y educadoras, para quienes la condición indígena o afrodescendientes es objeto de subvaloraciones y prejuicios heredados de una larga historia de discriminación epistémica, lo que Santos Ilamaría injustica cognitiva (2011). Otro asunto asociado 
al fenómeno de la invisibilidad en las políticas educativas es el que concierne al ocultamiento de la situación de crisis de derechos humanos y vulnerabilidad de la primera infancia indígena y afrocolombiana.

El problema radica en que dos décadas de destierros forzados han puesto a familias indígenas y afrodescendientes en el frío pavimento de ciudades que no están listas para atender la dignidad de sus culturas ancestrales. Las estadísticas son contundentes, en Bogotá, Medellín y Cali la presencia étnica ha crecido de modo significativo en lo que lleva el siglo xxı. Madres afrocolombianas desterradas, mujeres indígenas amenazadas, autoridades y sabedores presionados por el poder de la minería armada, son los grandes protagonistas de este nuevo capítulo de nuestra historia que combina diferenciación e integración. Sin embargo, las educadoras y el sistema en el cual desarrollan su trabajo en educación inicial o atención a la primera infancia, no están preparadas para tramitar las demandas y necesidades de estos nuevos habitantes de la ciudad. Como lo señala Arias (2011), el desplazamiento forzado hacia las ciudades pone en riesgo la pervivencia de las costumbres, la cosmovisión, las creencias religiosas, la medicina natural y la lengua de los pueblos indígenas y de las comunidades afrodescendientes. Las familias enfrentan una crisis de vínculo en la ciudad, especialmente porque en estos contextos "las maneras de pensar, actuar y asumir la realidad guardan una relación directa con las prácticas del mundo occidental"(p.65).

Las primeras aproximaciones a estos fenómenos nos han mostrado la complejidad histórica que contiene el asunto de poblaciones indígenas y afrodescendientes desplazadas al mundo de las ciudades. Confluyen aquí los viejos problemas de una nación autorrepresentada en el mestizaje que transitó el siglo xx en la idea del progreso como vida urbana.

\section{Racismo, repitencia y silenciamiento}

Las narraciones que se presentan a continuación son una pieza de un entramado complejo, diverso y disperso que junta cientos de vivencias de niños que padecen en las ciudades a donde han sido desterrados, una doble condición de vulnerabilidad, de una parte, por su condición de víctimas del desplazamiento o la migración forzada, también por su condición de pobreza extrema, y en otro nivel por su condición cultural étnica-racial que les hace objeto de discriminaciones en el mundo de la calle, la escuela y el barrio. Estos tres testimonios provienen de menores de edad cuya experiencia escolar transcurre en las localidades de Ciudad Bolívar, Bosa y Barrios Unidos, en la ciudad de Bogotá. Los nombres de los niños y la niña se han cambiado para salvaguardar la confidencialidad que corresponde.

\section{El destierro de Jefferson}

Jefferson tiene seis años que parecen cien. Viene desplazado del Urabá chocoano. Vive en la localidad de Bosa, en una habitación, donde tienen dos camas en las que duermen los cuatro niños y la madre. Su padre está en la cárcel hace más de un año.

Con apenas siete años, y cursando primero de primaria, Jefferson carga con el peso de ser un niño afrocolombiano en una ciudad mayoritariamente mestiza, hijo de una familia desmembrada por la violencia estructural que azota a las poblaciones del Pacífico desde hace varios años.

"Cuando Jefferson llegó a la escuela -dice su profesora-, la maestra a cargo del grupo dijo: 'Yo no quiero a ese negro en mi salón', y tocó buscarle otro grupo, pero el niño oyó eso, y nunca se le va a olvidar".

La maestra de Jefferson está preocupada:

El niño la pasa mal. Son tres hermanitos, y la madre es muy joven. A ella le toca salir muy temprano a trabajar, entonces los más grandes quedan a cargo de los pequeños... Fíjese, Jefferson tiene una chamba en la frente porque se quemó con aceite caliente haciendo el almuerzo.

Jefferson ha cambiado mucho, ahora es agresivo, y dice que no quiere ser negro, que no le gusta ser negro. Les pega a sus compañeritos, les toca la cola y les levanta la falda a las niñas. Anda muy triste y parece incontrolable... A veces se queda callado, como congelado en el tiempo, como si se hubiera ido a "otra parte". 
La maestra sabe que el dueño del inquilinato donde vive la familia de Jefferson, lo maltrata y posiblemente abusa de él. Varias veces lo ha amarrado a la cama, dizque porque es muy inquieto. La maestra sospecha que están pasando cosas muy malas con la vida de ese pequeño, y sus ojos se humedecen cuando recuerda cómo era Jefferson hace dos años, cuando llegó por primera vez a su salón: "Era un niño cariñoso y tranquilo, no como ahora que es agresivo".

\section{El silencio de Rosita}

Rosita tiene 5 años y nació en Bogotá. Es hija de la comunidad indígena embera chamí que desde 2007 se asentó en la capital del país, debido a la guerra que les hizo abandonar su territorio ancestral de ríos y ensenadas en la selva chocoana. La familia de Rosita, al igual que otras 120, vivieron en albergues durante casi dos años, hasta que en 2012 recibieron apoyo institucional y se ubicaron en una zona del centro de la ciudad en viejos inquilinatos. Las mujeres venden en la calle las artesanías que fabrican diariamente con chaquiras e hilos de colores. Rosita estuvo hasta los cuatro años bajo el cuidado de su familia. Aprendió con su tía y su madre la lengua embera y por eso el castellano es su segundo idioma de uso. Actualmente ella asiste a grado primero en una escuela en la localidad de San Cristóbal.

La profesora de Rosita dice que es muy difícil trabajar con la niña, pues ella es muy callada, no la prepararon en un preescolar, participa poco, no juega con los otros niños y no logra avanzar en su proceso de alfabetización. Reconoce que, al principio, los demás niños y algunas niñas se burlaban de ella por su pelo y la forma como viste la tía que la recoge a la salida de la escuela. "Eso es cosa de niños, ellos son así", dice la maestra recordando que alguien de la comunidad reclamó al rector por esta situación. A Rosita le gusta cantar cuando está en su casa, y repite las tonadas que aprendió son su familia, y es una muy buena tejedora que aprende rápido la técnica de manillas. La madre de Rosita quiere que la niña no sufra la discriminación y el rechazo por hablar mal el castellano y no entender bien la vida en la ciudad, así que insiste en que estudie en una escuela normal como todos.

\section{Andrés, el repitente indígena}

Andrés nació en 2001 en el Huila. Su papá se Ilama Clímaco y su mamá, Ana Cecilia; ambos son indígenas, pero no hablan el idioma propio, y los dos son sobrevivientes de la tragedia de 1994 en Tierradentro. En noviembre de 2013 Ilegaron Andrés y su familia al terminal de transporte de Bogotá, con $\$ 100.000$, tres cajas con ropa, y un costal con plátanos, fríjol y dos kilos de maíz. Dejaban atrás la vida en el resguardo, la escuela bilingüe y la crisis cafetera que los dejó en la ruina. Clímaco empezó a trabajar mezclando cemento, y a cambio consiguió una pieza para vivir con Ana Cecilia y sus tres hijos. A las pocas semanas habían inventado un hogar en cinco metros cuadrados, con un colchón viejo y unas cuantas cobijas para batallar con la temperatura de la madrugada. Fueron al Cadel para informar que eran indígenas y necesitaban un cupo para que sus hijos empezaran a estudiar en febrero de 2014. Andrés comenzó el grado sexto con muchas dificultades. Su hermanito estaba llegando a los diez años, y lo habían matriculado en grado tercero. Para mayo, la vida familiar se había estabilizado, trabajaban mucho y ganaban poco, pero sobrevivían cada mes. Entonces empezaron los problemas de Andrés en el colegio. La profesora se quejaba por su bajo rendimiento, e insistía en que ese era el problema con los niños que venían de fuera. Andrés y Miguel Ilegaban del colegio hacia las cuatro y media de la tarde, y se ponían a lavar botellas hasta las nueve de la noche. No había tiempo para tareas ni cosas de esas. Andrés cumplió los 13 años en noviembre y a los pocos días le anunciaron que había reprobado casi todas las materias, y entonces debía repetir el mismo grado. Comenzó 2015 y Andrés pasaba malos ratos en el colegio porque no tenía amigos, no entendía las clases y se sentía viejo en medio de tantos niños de 10 y 11 años. Debido a sus dificultades para leer, escribir y hacer cálculo matemático, Andrés no logró aprobar el grado sexto, y en consecuencia ya no siguió estudiando, vive muy triste y extraña a su maestra Elvia, la del resguardo, que le enseñaba historias del trueno y Juan Tama, y le decía que era un buen estudiante. 


\section{Las historias de hoy hablan del pasado colonial}

Cuando alguien, con la autoridad de un maestro, describe el mundo y tú no estás en él, hay un momento de desequilibrio psíquico, como si te miraras en el espejo y no vieras nada.

Adriene Rich (Invisibility in Academe)

Las historias de Jefferson, Rosita y Andrés son la memoria de lo que Jurgo Torres (2013) Ilama injusticia curricular, para señalar que durante dos largos siglos, la escuela y su conocimiento oficial han enseñado verdades a medias y mentiras como explicaciones de la historia. Esa injusticia que alimenta con cartillas, rondas infantiles y rituales escolares el racismo y discriminación que dominan las explicaciones del mundo, la sociedad y las personas que a diario circulan en cientos de miles de aulas. Cuando esto sucede en el mundo escolar adquiere especial relevancia porque compromete la experiencia emocional, moral y cognitiva de los niños, y produce mucho daño en su autoestima y autorreconocimiento.

Los lineamientos pedagógicos existentes para el ciclo de la educación inicial no contemplan aún las situaciones multiculturales como un rasgo en el aula, menos la intervención docente para garantizar el derecho a no ser discriminado. Justamente por esta razón en Bogotá ha cobrado fuerza este debate, con la finalidad de reconocer que la ciudad hoy en día tiene poblaciones diversas, niños y niñas pertenecientes a culturas indígenas, como el caso de Rosita, y que eso debe estar incluido en las políticas educativas y en los proyectos educativos institucionales (PEI) de las entidades educativas, para que Rosita en su condición como embera asista a la escuela siendo diferente pero igual en materia de derechos.

Por racismo escolar estamos entendiendo el conjunto de prácticas simbólicas y discursivas orientadas a subvalorar a los niños afrocolombianos a través de todos los dispositivos que la escuela provee -textos en su acepción más amplia, lenguajes, políticas de conocimientos y pautas de socialización-, así como las interacciones de la vida cotidiana que se manifiestan en chistes, apodos y rechazo hacia los niños afrodescendientes e indígenas. En el caso de estos últimos, el rasgo lingüístico es especialmente sensible dado que, en muchos de los casos de población en situación de desplazamiento, los niños pequeños tienen el castellano como segunda lengua, haciendo entonces mucho más dramática su interacción en un medio totalmente monolingüe como el de los centros educativos de Bogotá o Medellín, por ejemplo. El racismo que acontece en el marco de los procesos pedagógicos y de socialización primaria de los niños, no puede ser analizado, ni tampoco intervenir al margen de los factores exteriores escolares, pues el racismo escolar constituye una pequeña expresión del racismo estructural.

Hasta ahora, los estudios realizados en Colombia sobre el racismo escolar ${ }^{3}$ han considerado solo sus planos interiores, es decir, se ha leído desde sus propios dispositivos de funcionamiento, lo cual ha limitado el análisis a la cultura escolar, y sus dispositivos de funcionamiento -textos, currículos, políticas de conocimiento y la administración educativa-. Si bien es cierto, estos estudios han sido valiosos para comprender cómo el racismo se manifiesta en el sistema educativo, consideramos que existen planos exteriores que están íntimamente relacionados con esta problemática, los cuales nos llevan a pensar que el racismo escolar es solo el síntoma de proceso más complejo. Se trata de una ideología que trasciende el mundo de las aulas y la pedagogía, y proviene de las redes representacionales racializadas en las cuales la sociedad colombiana fundó su existencia a finales del siglo xIx.

Un segundo asunto tiene que ver con los imaginarios regionales con los que nos hemos construido como nación. Quizás movidos por lo que Wade (2000) denominó topografía racial, creemos que en Colombia existen ciudades negras y ciudades blancas o mestizas. Bogotá representa una de las últimas, y esta imagen que se ha transformado por la fuerza de los acontecimientos, hace que todavía predomine la idea de la capital como ciudad del mestizaje, por el cual las políticas públicas para la primera infancia están diseñadas para niños mestizos como paradigma de homogeneidad, dejando de lado la presencia de un número cada vez más amplio de niños afrocolombianas o indígenas en los jardines y en las escuelas. Esto explica, en parte,

\footnotetext{
3 Un primer estudio sobre racismo escolar en Bogotá fue realizado en 2009 por María Isabel Mena en el marco del Proyecto Dignificación de los Afrodescendientes y de su Cultura a través de la Etnoeducación en Colombia, Investigando el Racismo y la discriminación racial en la Escuela. Informe Ejecutivo. Bogotá, Colombia.
} 
por qué las políticas públicas de la capital en materia de asistencia infantil siguen ancladas en el modelo de un niño universal, lo cual lleva a que no existan políticas diferenciadas para tramitar los problemas que afectan a los niños afros migrantes y desplazados. Si la ciudad vive aún en un imaginario mestizo, las políticas públicas reproducen en su intervención el mismo paradigma. En este sentido, la infancia afrocolombiana y los problemas que la aquejan en su vida cotidiana está desamparada por las políticas del distrito en materia de derechos que protejan su vulnerabilidad como personas discriminadas por raza y cultura.

El tercer asunto tiene que ver la preponderancia de un imaginario mestizo en todos los planos de las políticas comprometidas con la infancia, desde aquellas que se promueven en las facultades donde se forman las maestras y educadores infantiles, pasando por quienes producen y diseñan los contenidos de las cartillas y los textos de educación inicial, hasta los diseñadores de programas y proyectos de primera infancia. Domina entonces la matriz andinocéntrica que tiene como modelo el mestizaje y por ende silencia e invisibiliza la diferencia indígena y afrodescendiente. Sumado a este hecho, asistimos hoy al fenómeno de la waltdisneización de la escuela y sus aulas (Castillo y Caicedo, 2009. A este respecto, Jurgo Torres (2013) ha señalado que esto sucede en la escuela debido a que se pretende mantener a los chicos "en una especie de limbo, o de paraíso artificial". También ocurre, según este autor, que se producen materiales curriculares artificialmente infantilizados que incrementan el clasismo, el sexismo, y el racismo promovido por multinacionales del tipo de Walt Disney. De esta manera podemos reconocer entonces que los textos iconográficos presentes en murales, carteleras y paredes de las aulas de educación inicial, trasmiten valores y creencias, es decir son también contenidos ideológicos, y en esa medida adquieren un papel fundamental en la formación de niños cuando exaltan princesas, héroes, caricaturas, animales, entre otros. No se trata de un material que simplemente entretiene o decora un espacio físico, consiste en una mediación simbólica que opera también con referentes de identificación con lo bello, lo bueno, lo deseable. En el caso de la ambientación del aula su waldisneización poco dice de la vida, la cultura, la ancestralidad y la territorialidad de los niños de Bogotá que habitan cotidianamente estos espacios. Por el contrario, estas imágenes y sus significados no forman parte de los intereses de los niños, por el contrario, invisibilizan su realidad cultural, familiar y social.

En el caso de cartillas, libros de cuentos, materiales de aprestamiento y juguetes, es fundamental analizar la representación de las figuras humanas que se ofrece a los niños, donde por lo general prevalecen imágenes estereotipadas como rosadas y casi nunca se presentan personas con situaciones de discapacidad motriz o visual, o personas en situación en sillas de ruedas o con muletas. Más allá de las teorías sobre la multiculturalidad y todas sus arandelas, el hecho concreto es que nuestras culturas escolares y nuestros currículos hoy en día todavía reproducen saberes que estereotipan, ocultan o reducen la historia y la cultura de las personas afrodescendientes. Es tan grave la situación que en nuestra cultura profesoral, prevalece la idea de un color piel, que corresponde a la tonalidad del rosado, y entonces los niños de casi todo el país aprenden a colorear las siluetas corporales con un lápiz de color rosado, que heredó la sustancialidad cromática de la piel humana. El rosado gobierna como emblema de nuestra epidermis en este trópico colonizado por la vieja idea de la superioridad racial. Esto es un sesgo racista cultivado desde la Colonia, pasado por la instrucción pública decimonónica y madurado en las cartillas y textos escolares con los que se enseñó que lo bonito es lo clarito. Todo este complejo fenómeno abarca un conjunto de materiales educativos alfabéticos y no alfabéticos, cuyas narrativas y formas discursivas cumplen una función significante, y que incluyen las canciones y rondas infantiles, los juegos de aula, las iconografías del aula, los libros de literatura infantil, los juguetes, los muñecos y los artefactos (Castillo y Caicedo, 2009). Todos estos objetos culturales son mediadores simbólicos en los procesos de socialización primaria que acontecen en el universo de las diversas modalidades de educación escolar.

Otro elemento a mencionar se refiere a que el racismo produce afectaciones subjetivas en las personas discriminadas. Me refiero a la experiencia subjetiva que produce impactos en el orden emocional y psicológico en los niños. Se trata del impacto en las identidades individuales que se manifiesta en baja autoestima, autonegación y falta de reconocimiento de los sujetos vulnerados por el racismo. En este sentido consideramos que el 
racismo no constituye solamente una práctica de orden pedagógico, sino fundamentalmente de orden subjetivo. Las formas como el racismo opera dentro y fuera de la escuela llevan a que los niños afrocolombianos sientan pena por su propia condición racial y en muchos casos hasta sean hostiles con personas afrocolombianas. Esto se expresa en situaciones como la soledad en el aula, distanciamiento frente a los demás niños, baja autoestima, crisis de identificación y, muchas veces, una larga travesía por el autodesprecio.

En el caso de los niños indígenas y afrocolombianos en situación de desplazamiento, esto es más complejo, porque además de sufrir el racismo por rasgos fenotípicos, experimentan el racismo cultural, que se expresa en burlas por su forma de hablar, en muchos casos incomprensión por parte de las docentes que no entienden que son niños que provienen de lugares donde los ritmos de vida, las comidas y el clima son diferentes. Esto lleva a que en muchos casos se considere que los niños afrocolombianos son menos hábiles para las actividades escolares o que debido a los cambios de contexto su adaptación sea lenta, lo que no se ve como tal, sino que, por el contrario, se raye en explicaciones estereotipadas.

Hoy día, cuando el drama del racismo y la discriminación se hace notorio en aulas y escuelas citadinas, y sabemos que los niños sufren a diario los estragos de esta vieja patología social, debiéramos revisar la historia y reconocer que mucho antes que fuera tan famosa en libros y congresos, la interculturalidad ha sido un viejo reclamo en esta nación de olvidos ilustres. Los relatos de Jefferson, Rosita y Andrés son la expresión de este nuevo rostro del multiculturalismo del siglo xxı, y de una escuela oficial que no se ha dispuesto aún para dar cabida a la existencia de diversidades y diferencias históricamente signadas por el racismo y la discriminación.

\section{Insistencias finales}

Nuestra larga historia colonial de relaciones de poder basadas en la clasificación de razas, culturas y clase produjo una tremenda asimetría entre la sociedad denominada mestiza y los pueblos y culturas considerados indios y negros. Ello explica las razones por las cuales vivimos en un continente de exclusiones radicales y legitimadas ideológicamente en la creencia de la superioridad racial. Todo esto ha producido en una larga cadena de acontecimientos nuestro colonialismo interno, como diría Gonzales Casanova. Así que lo que abordemos en relación con la etnicidad del siglo XXI está afectado de modo directo por estas relaciones de dominación que determinaron nuestro rumbo durante tres largos siglos de vida como colonias de ultramar, en lo que Wallerstein ha llamado configuración del sistema mundo. Aunque suene algo anacrónico, nuestras experiencias contemporáneas con el reconocimiento de la diversidad, la diferencia y la multiculturalidad se encuentran profundamente afectadas por cómo aprendimos a vernos y a ser vistos durante los siglos anteriores. En ese sentido, se propone una lectura histórica sobre los debates que actualmente irrumpen en el mundo educativo para referirse a fenómenos que son viejos en su existencia, pero novedosos en su forma de representación y enunciación. En este caso particular, se hace énfasis en tres planos concretos: el primero referido a las luchas educativas de indígenas $y$ afrodescendientes en el siglo xx; el segundo, a los cambios de época que han vivido estos pueblos y culturas debido al conflicto armado en Colombia, y el tercero, el escenario de una educación no racista y no discriminadora como alternativa a los procesos herederos de la antigua experiencia colonial y su clasificación de personas, clases y razas. En ese sentido, es sensato afirmar: "No todas las diferencias son iguales", y ello redunda en reconocer que las diferencias, como rasgos que distinguen unos seres humanos de otros, son construcciones históricas, estrategias de gobierno que cumplen una función modeladora en cada momento preciso. En palabras de Skliar (2005), este diferencialismo constituye una invención para gobernar. La invención de lo indio y lo negro, como bien lo han explicado autores como Bonfil Batalla (1972), respectivamente, constituyen la Ilave esencial de una condición colonial impuesta a poblaciones que se ubicaron en el sistema de producción económica de un siglo que demandaba dominios de raza y origen para la invención de América. Esta tremenda sociogénesis de nuestras naciones es fundamental para comprender por qué las estadísticas asociadas con analfabetismo, desnutrición, pobreza y violación de derechos humanos se concentran entre los cerca de 210 millones de indígenas y afrodescendientes que pueblan el continente. 


\section{Referencias}

Arias, L. (2011). Indígenas y afrocolombianos en situación de desplazamiento en Bogotá. Trabajo Social, 13, 61-76. Recuperado el 14 de abril de 2017 de: http://www.revistas.unal.edu.co/index. php/tsocial/article/view/28365/38859

Bonfil Batalla, G. (1972). El Concepto de Indio en América: Una Categoría de la Situación Colonial. Anales de Antropología, vol. IX, UNAM (México).

Castillo, E. y Caicedo, J. (2009). Negritud sin afrocolombianidad. Aproximación a los textos escolares de educación inicial. Recuperado de: http://www.academia.edu/23725788/Negritud_sin_afrocolombianidad._Aproximaciones_a_los_textos_de_la_educaci\%C3\%B3n_inicial_en_Colombia

Centro Nacional de Memorias Histórica (2013). ¡Basta ya! Colombia: Memorias de guerra y dignidad. Bogotá: Imprenta Nacional.

Santos, B. (2011). Introducción: las epistemologías del sur. En: I. Vianello y B. Mañé (eds.). Formas-Otras. Saber, nombrar, narrar, hacer. Memorias IV Training Seminario de jóvenes investigadores en Dinámicas Interculturales (pp. 9-22). Barcelona, España: Centro de Estudios y Documentación Internacionales de Barcelona (CIDOB).

Mena, M. (coord.) (2010). Si no hay racismo no hay Cátedra de Estudios Afrocolombianos. Bogotá: Proyecto Dignificación de los y las Afrodescendientes y de su Cultura en Colombia.

Secretaría Distrital de Integración Social SDIS - OEI (2011). Lineamiento Pedagógico para la Educación Inicial Indígena En Bogotá. Sigma Editores.

Skliar, C. (2005) "Poner en tela de juicio la normalidad, no la anormalidad. Argumentos a falta de argumentos con relación a las diferencias en educación". En Vain, P. y Rosato, A. (Coord.) La construcción social de la normalidad. Buenos Aires: Novedades educativas.

Torres, J. (2013). La justicia curricular. El caballo de Troya de la cultura escolar. Madrid: Ediciones Morata.

Wade, P. (2000). Raza y Etnicidad en Latinoamérica. Quito: Ediciones Abya Yala.

\section{Diálogo del conocimiento}

\section{Bordes y fracturas de la escuela}

Para muchos, la historia educacional del siglo xIx fue la conquista progresiva de la escuela como una institución social accesible a toda la población. La visión elitista del siglo xix consideraba a la escuela un privilegio de las clases altas, perspectiva que aún está presente en las discusiones actuales, especialmente cuando hablamos de cobertura en educación superior.

El artículo de Elizabeth Castillo Guzmán nos invita a reflexionar sobre el contenido final que está tras el acceso a las escuelas de nuestro continente. Los niños, niñas y jóvenes retratados en sus páginas no son los protagonistas de una pedagogía inclusiva. Su foco en los márgenes nos ayuda a comprender los límites del discurso de las reformas educativas que defienden la idea de una escuela centrada en el alumno. Pero ¿quién es este alumno tipo? Nos encontramos aquí con escritos clásicos de Pierre Bourdieu, Christian Baudelot y Roger Establet, referentes de la discusión sobre el rol de la escuela en la reproducción de las desigualdades. El alumno tipo tiene una clase social definida, un género determinado y una etnia estándar. Entonces, los estudiantes desplazados, producto de la violencia institucionalizada, se encuentran trasplantados en espacios escolares de las ciudades colombianas. Y allí el conflicto se retrotrae al ámbito psicológico individual, donde solo parece viable el abandono o la renuncia identitaria.

La realidad colombiana retratada en este artículo encuentra un eco en otras latitudes. Estas mismas miradas perdidas las encontramos en la infancia migrante en las escuelas de Buenos Aires, Santiago, Sao Paulo, Ciudad de México, y Texas. El desplazamiento es un fenómeno social que se inscribe en la psicología infantil como un rechazo, un abandono, una pérdida y un duelo. Las escuelas difícilmente logran hacerse cargo de estos procesos y optan por el statu quo y la aplicación de la norma. Por lo tanto, este trauma original se actualiza y profundiza en la violencia simbólica y el currículum oculto de las mismas escuelas.

El texto de Elizabeth nos convoca hacia los márgenes. Solo es posible cuestionar la institución desde las fronteras. La escuela no es solamente un espacio de reproducción de las desigualdades, sino también un escenario de liberaciones como diría Paulo Freire. Los intersticios de este conflicto de conservación y transformación son los que permiten que puedan emerger trabajos de investigación, reflexiones pedagógicas, y luchas comunitarias por un derecho a la educación de un nuevo orden. Esta es una agenda para construir una nueva epistemología y una nueva política; una transformación que puede incluir la introducción de lingüística y cultural de las minorías indígenas en una escuela definida como un lugar de encuentro multinacional. La visibilidad de este fenómeno nos ayudará construir una pedagogía de la acogida. Esta protección es básica para mitigar los efectos de los destierros y exilios contemporáneos en nuestras infancias.

Jorge Inzunza 